\title{
CORRECTION
}

H. Alıci(i) - T. Tanriverdi

\section{Correction to: General Solution of the Schrödinger Equation for Some Hyperbolic Potentials}

Published online: 26 November 2020

(C) Springer-Verlag GmbH Austria, part of Springer Nature 2020

\section{Correction to: Few-Body Syst (2020) 61:41}

https://doi.org/10.1007/s00601-020-01575-z

Unfortunately, corrections to equations 3.19 and 3.20 were published incorrect in the original publication. The correct version of Eqs. 3.19 and 3.20 updated here.

$$
\begin{array}{r}
\lambda \in S_{m+1}=\left\{-1,-9, \ldots,-(2 m+1)^{2}\right\} \\
\lambda \in T_{m}=\left\{0,-4,-16, \ldots,-(2 m)^{2}\right\}
\end{array}
$$

The original article has been corrected.

Publisher's Note Springer Nature remains neutral with regard to jurisdictional claims in published maps and institutional affiliations.

The original article can be found online at https://doi.org/10.1007/s00601-020-01575-z

H. Alıcı (凶). T. Tanriverdi

Department of Mathematics, Harran University, 63050 Şanlıurfa, Turkey

E-mail: haydara@harran.edu.tr

T. Tanriverdi

E-mail: ttanriverdi@harran.edu.tr 